\title{
A FALTA DE CLAREZA DO PAPEL DO COORDENADOR PEDAGÓGICO E COMO ISSO AFETA O COTIDIANO DA ESCOLA
}

\author{
PENTEADO, Maria Emiliana Limaㅎ GOMBOEFF, Ana Lucia Madsen².
}

\section{RESUMO}

Neste artigo é apresentada uma análise realizada, com base nos pressupostos teóricometodológicos da Psicologia Sócio-Histórica (PSH), dos relatos de quatro coordenadores pedagógicos (CPs) de escolas públicas da rede municipal de ensino de São Paulo (RMESP). O objetivo geral foi analisar as significações acerca do papel dos CPs, a partir de relatos produzidos por eles que indicavam descompasso com o que eles entendiam ser parte de suas atribuições e o que os outros gestores pensavam ser o papel desses profissionais, a fim de compreender como essa divergência pode afetar o trabalho em equipe e como se reverbera na escola. Os resultados indicaram que aos membros da equipe gestora há falta de clareza do que seria, realmente, o papel do $\mathrm{CP}$, evidenciando aspectos que apontam determinada relação de poder, prejudicial ao trabalho pedagógico em equipe.

Palavras-chave: Coordenador pedagógico. Diretor. Relação de poder.

\begin{abstract}
The analysis that will be presented in this article is based on the theoretical-methodological assumptions from the Socio-Historical Psychology and of reports from four pedagogical coordinators of public schools that are part of the municipal school system of São Paulo. The overall objective was to analyze the meanings about the role of pedagogical coordinators perceived from reports produced by them that indicated mismatch with what they understood to be part of their attribution and what other managers thought was the role of these professionals in order to understand how this divergence can affect teamwork and how it reverberates in school. The results indicated that there is some dimness in the idea perceived by the members of the management team about what the role of the pedagogical coordinators really would be, pointing aspects that indicates a certain power relation that is detrimental to pedagogical teamwork.
\end{abstract}

Keywords: Pedagogical coordinator. School principal. Power relation.

\footnotetext{
${ }^{1}$ Doutora e Mestre em Educação: Psicologia da Educação pela PUC-SP. Pedagoga e Psicopedagoga. Pesquisadora no Grupo Atividade Docente e Subjetividade - GADS da PUC-SP e no projeto PROCAD (edital 071/2013) Tecendo Redes de Colaboração no Ensino e na Pesquisa em Educação: um Estudo sobre a Dimensão Subjetiva da Realidade Escolar, coordenado pela Profa. Dra. Wanda Maria Junqueira de Aguiar. Coordenadora Pedagógica na Rede Municipal de Ensino de São Paulo. Docente nos cursos de graduação e pós-graduação das Faculdades Integradas Campos Salles - FICS. Professora convidada em diversas Instituições de Ensino Superior - IES. Ministra cursos de formação para educadores das redes pública e particular de ensino.

${ }^{2}$ Doutoranda em Educação: Psicologia da Educação pela PUC-SP. Mestre em Educação: Formação de Formadores pela PUC-SP. Pedagoga. Pesquisadora no Grupo de pesquisa: Rede de estudos e pesquisas de desenvolvimento profissional docente - REPED da PUC-SP, coordenado pela Profa. Dra. Marli André. Coordenadora Pedagógica da Rede Municipal de Ensino de São Paulo. Ministra cursos de formação para educadores das redes pública e particular de ensino.
} 


\section{Introdução}

O objetivo geral do estudo foi analisar as significações acerca do papel dos CPs, a partir de relatos produzidos por eles que indicavam descompasso com o que eles entendiam ser parte de suas atribuições e o que os outros gestores pensavam ser o papel desses profissionais, a fim de compreender como essa divergência pode afetar o trabalho em equipe e como se reverbera na escola. Os objetivos específicos foram: explicitar e explicar como o $\mathrm{CP}$ compreende o seu papel e como os demais gestores que atuam com ele significam o papel dele e, ainda, expor como as relações de poder se revelam nas situações cotidianas nas unidades escolares, explicando suas reverberações na instituição.

Os relatos analisados foram enviados por e-mail e WhatsApp a partir da solicitação das pesquisadoras. Na análise dos dados, toma-se como base os pressupostos teóricometodológicos da Psicologia Sócio-Histórica, que se fundamenta no Materialismo HistóricoDialético, partindo do pensamento de autores como Vigotski ${ }^{3}$ e seus seguidores, bem como de autores contemporâneos que comungam dos mesmos referenciais.

Apresenta-se, inicialmente, o posicionamento teórico-metodológico adotado que garante o rigor necessário para aprofundar a análise, discussão e considerações finais. Em continuidade, contextualiza-se a realidade pesquisada, explicando quem são os sujeitos participantes deste trabalho e esclarecendo a forma como os dados foram produzidos e analisados. Prossegue-se expondo a análise realizada. Por fim, delineiam-se as considerações finais com alguns questionamentos e proposições sobre a questão da necessária clareza do papel do CP e suas reverberações na escola.

\section{Posicionamento teórico-metodológico: Psicologia Sócio-Histórica}

Para manter coerência e rigor científico, as teorizações estão embasadas nos princípios da Psicologia Sócio-Histórica (PSH), assentados no pensamento de Lev S. Vigotski (18961934), Alexander Romanovich Luria (1902-1977) e Alexis Nikolaevich Leontiev (1903-1979), que, por sua vez, sedimentam suas ideias nos pressupostos teórico-metodológicos do

\footnotetext{
${ }^{3}$ Por não haver ainda uma padronização na forma de grafar o nome do autor (VYGOTSKY, VYGOTSKI, VIGOTSKI), optou-se por utilizar, neste artigo, a grafia Vigotski, que vem sendo utilizada em recentes trabalhos publicados no Brasil.
} 
Materialismo Histórico Dialético (MHD), de Karl Marx (1818-1883) e Friederich Engels (1820-1895).

Na perspectiva da PSH, compreende-se significações como a articulação dialética dos sentidos e significados, um par dialético, ou seja, se constituem mutuamente, mas um não é o outro e um não é sem o outro, pois a existência de um carrega a existência do outro. Os sentidos são produções singulares e complexas e, portanto, menos estáveis, com processo de transformação mais dinâmico porque representam a leitura particular e única, embora constituída a partir do significado, que cada sujeito constrói da realidade. Os significados são produções histórico-culturais que oportunizam a comunicação dos homens por serem mais estáveis e dicionarizados, embora possam se modificar (VIGOTSKI, 2001).

\section{Sobre a realidade pesquisada: sujeitos da pesquisa e instrumentos de produção e análise de dados}

A pesquisa foi realizada com cinco CPs da RMESP. Quatro participantes são mulheres e um é homem. Os relatos 1 e 2 pertencem à mesma CP. Ela tem vinte e cinco anos dedicados à Educação, sendo: quinze na sala de aula e dezoito como CP. Tem formação em Letras e Pedagogia e mestrado concluído. O relato 3 foi feito por uma $\mathrm{CP}$ que tem vinte anos de carreira, sendo quinze na RMESP, oito como professora e sete como CP. Ela atuou na sala de aula em outra rede de ensino pública, bem como na rede particular. Tem formação em Pedagogia e mestrado concluído. O relato 4 foi elaborado por uma CP que é formada em Letras e Pedagogia e possui pós-graduação em Gestão Educacional. Trabalhou na RMESP durante vinte e seis anos e hoje está aposentada há dois anos. Atuou na coordenação pedagógica por sete anos como CP designada. O CP responsável pelo relato 5 trabalha na RMESP desde 1992, ou seja, vinte e seis anos. Formado em História, foi professor até 2003. No ano seguinte, tornou-se CP. Tem mestrado e doutorado concluídos.

O procedimento utilizado para produção dos dados foi a rede social WhatsApp, com a seguinte consigna:

Bom dia, amiga/o,

Estou escrevendo um artigo. Pretendo escrever junto com uma amiga da PUC-SP e queremos tratar das relações de poder entre o CP e o diretor e a falta de clareza do diretor e seus assistentes quanto ao trabalho do CP. Para fazer isso estou recolhendo relatos verídicos de situações vividas pelos CPs. Não haverá nenhum tipo de identificação da escola nem do $\mathrm{CP}$ ou diretor. Caso possa e queira contribuir ficaria muito agradecida. Você pode me encaminhar o relato por e-mail ou gravar um áudio e me mandar pelo WhatsApp, se preferir. Desde já agradeço, caso possa participar. Penso que escrever de forma acadêmica, séria e sem revelar nomes é uma forma de tentarmos mudar a realidade. 
Oito CPs receberam a mensagem via WhatsApp e cinco responderam. Os cinco relatos foram incorporados à análise.

Para analisar os dados produzidos, utilizou-se o procedimento metodológico de análise e intepretação Núcleos de Significação (NS) (AGUIAR; OZELLA, 2006, 2013; AGUIAR; SOARES; MACHADO, 2015). Tal procedimento atende aos pressupostos da PSH, pois analisa e interpreta dialeticamente os dados.

Para realizar a análise dentro da proposta dos NS, inicialmente leu-se sistematicamente os relatos. Essa etapa é primordial para que o pesquisador se aproprie da realidade pesquisada e, desse modo, consiga situá-la no seu contexto histórico local, social, político e ideológico.

A partir daí, efetuou-se o levantamento dos pré-indicadores, ou seja, escolha de trechos compostos por "palavras cujos significados carregam e expressam sempre a materialidade histórica do sujeito, isto é, aspectos afetivos e cognitivos da realidade da qual participa" (AGUIAR; SOARES; MACHADO, 2015, p. 62). Nesse momento, partiu-se do que é visível, isto é, o empírico, expresso na fala do participante, observando aspectos singulares, como a frequência, a ênfase e a reiteração de determinadas palavras e expressões, bem como a carga emocional que as constitui.

Em seguida, aprofundou-se a análise com o levantamento dos indicadores. O que configura essa etapa da produção dos NS é a articulação dos pré-indicadores (empírico) por suas semelhanças, complementaridade e contradição.

Por último, produziram-se os NS, articulando os indicadores por suas semelhanças, complementaridade e contradição. Trata-se da síntese mais elaborada no decorrer do processo analítico que visa a teorizar e explicar os nexos que constituem a realidade pesquisada.

\section{Análise e intepretação dos dados: Núcleos de Significação}

Depois de executar todo o processo referente ao procedimento metodológico adotado, três NS foram construídos. Parte do título deles se constitui de duas frases retiradas dos relatos, que sintetizam os conteúdos tratados.

Núcleo 1 - As significações do diretor e seus assistentes sobre o papel do CP e a visão do CP sobre suas atribuições: "a assistente de direção nos interrompeu (PEA)... Casos de indisciplina e violência, praticamente não tinha tempo de fazer xixi ou almoçar". 
A questão central deste núcleo é explicitar e explicar como o diretor e seus assistentes significam a função do $\mathrm{CP}$ e como o próprio CP compreende o seu papel na RMESP.

Placco e Souza (2012) realizaram uma pesquisa, em diferentes regiões do Brasil, para compreender como os profissionais da escola concebiam a função do CP. O trabalho das autoras revelou que o $\mathrm{CP}$, segundo a compreensão dos diretores, pertence à gestão da escola, ou seja, é considerado um gestor, assim como o diretor e seus assistentes. No entanto, ao atribuir ao CP o papel de gestor, a direção compreende que esse profissional deve assumir as funções administrativas e organizativas que cabem à gestão escolar, afastando-o, muitas vezes, da dimensão pedagógica que deve ser o centro das suas ações. O relato abaixo exemplifica a ideia das pesquisadoras:

Relato 1 - Terça-feira, dia de PEA (Projeto Especial de Ação), isto é, momento
destinado para formação docente. [...] A assistente de direção nos interrompeu,
juntamente com uma mãe de aluno que havia sido convocada por ela. A mãe havia
saído do trabalho, utilizando seu horário de almoço, assim, não havia como solicitar
que aguardasse [...]. Cessei o trabalho formativo, pedi licença e saí da sala, visto que
não era a responsável pelo encaminhamento dos casos de indisciplina e também por
não concordar com a ação estabelecida [...]. A assistente de direção, ao invés de
assumir o encaminhamento do trabalho, saiu da sala gritando e criticando meu
posicionamento de forma muito desrespeitosa e acionou a direção que me abordou em
minha sala, também com a voz alterada e agressiva.

A CP se nega a assumir uma das funções que pertence à estância da gestão, que é a questão disciplinar. Além disso, ela afirma que "não concorda com a ação estabelecida", indicando que não adere ao fato da formação docente ser interrompida para atendimento de caso disciplinar.

De acordo com o Decreto $\mathrm{n}^{\circ} 54.453 / 2013$, que fixa as atribuições dos profissionais de educação que integram as equipes escolares das unidades educacionais da RMESP:

\footnotetext{
Art. 5 São competências do diretor de escola, além de outras que lhe forem cometidas, respeitada a legislação pertinente:

V - garantir a adoção das medidas disciplinares previstas nas normas de convívio do regimento educacional e registradas no projeto político-pedagógico da unidade educacional;

VI - aplicar as sanções aos alunos, quando for o caso (SÃO PAULO, 2013).
}

A CP demonstra conhecer a legislação, no entanto, a assistente de direção atribui à coordenação a tarefa de encaminhar a situação disciplinar - o que provoca tensão, já que a CP prioriza, naquela circunstância, o momento de formação docente, acreditando que esse é o seu papel, indo na contramão do que lhe é atribuído.

Placco e Souza (2012, p. 12) garantem que "os diretores, embora afirmem valorizar as funções pedagógicas dos CPs, na realidade acreditam que eles devem atender às múltiplas 
necessidades cotidianas da escola" - o que os sobrecarrega e os distancia, muitas vezes, da formação docente e do acompanhamento pedagógico das aprendizagens.

O CP é o responsável pela formação continuada dos docentes e pela elaboração, execução e avaliação do projeto pedagógico, no entanto, ele não é o único que deve responder por tais tarefas, já que elas se estendem a toda a equipe gestora (SOUZA; PETRONI; DUGNANI, 2015).

As significações expressas no relato 3 - "Justo eu que fazia toda a documentação burocrática, as pautas dos PEAs, projeto pedagógico, entre outros" - evidenciam o quanto os CPs, de forma geral, assumem sozinhos tarefas que são da equipe gestora. Percebemos na fala da $\mathrm{CP}$ preocupação em relação à proposta do projeto de formação continuada e também à elaboração e ao acompanhamento do projeto pedagógico.

No entanto, são atribuições que envolvem o coletivo e, portanto, precisam do envolvimento de todos, principalmente, da direção enquanto liderança. Ao assumir sozinha todas essas atribuições, a qualidade do acompanhamento do trabalho docente fica, muitas vezes, prejudicada pela sobrecarga de trabalho.

O relato 4 - “[...] participar da reunião pedagógica enquanto diretor, Ok, mas mudar a pauta na frente dos professores e deixar-nos numa situação constrangedora não foi uma experiência positiva, e sim uma medida de força! Imposição de poder" - explicita como essa diretora significa os processos formativos e como está distante do trabalho em equipe.

Considerando este relato, defende-se que a diretora, diferente do que indica a fala da participante, deveria participar dos processos formativos, desde o planejamento até a realização. O que se espera é que a equipe gestora esteja entrosada e engajada a fim de identificar as necessidades da escola, incluindo as formativas. Caso isso não ocorra, corre-se o risco de terse, na escola, situações análogas às apontadas na pesquisa de Penteado (2017), isto é, um hiato na relação entre professor e equipe gestora, o que provoca no corpo docente a sensação de estar abandonado e perdido.

Mate (2009) afirma que aos CPs são atribuídas muitas tarefas e que seu papel, muitas vezes, se confunde com as funções dos outros gestores (diretor e assistentes de direção), e Garrido (2003) garante que a função do CP não só é mal compreendida como também mal definida pela legislação, recentemente normatizada em textos legais, porém não legitimada (PLACCO; SOUZA, 2012). O relato abaixo exemplifica o posicionamento das autoras:

Relato 2 - [...] No dia dezessete de outubro fui afastada do trabalho pelo médico durante dez dias devido a esgotamento físico e mental. Desse modo, voltei a trabalhar 
no dia 29 e logo notei que os professores não tinham sido avisados sobre a escolha das obras literárias e muito menos do prazo final, que era dia 31 de outubro [...]. A direção não foi trabalhar no dia 29 e as assistentes de direção não se envolveram na situação [escolha e registro de obras literárias].

O Decreto n ${ }^{\circ} 54.453 / 2013$ não especifica em nenhum momento a quem cabe a tarefa de coordenar e orientar a escolha de livros didáticos ou literários, bem como o registro dessa escolha na ata e no sistema PDDE - Interativo. No entanto, o documento "Orientações Escolha PNLD Literário 2018”4, encaminhado às escolas pelo MEC por meio do correio eletrônico (email da escola), afirma que a escolha das obras literárias deveria ser realizada conjuntamente entre o corpo docente e o dirigente da escola com base na análise e discussão das informações contidas no Guia do PNLD Literário, tendo-se como referência a proposta pedagógica escolar. Além disso, apenas o diretor da escola poderia realizar o registro dos livros escolhidos pelo corpo docente no sistema, já que esse registro somente seria possível mediante CPF e senha dele.

Mesmo com a ausência da $\mathrm{CP}$, a direção e as assistentes de direção (ADs) não se envolveram na escolha e no registro das obras literárias. Isso ocorre porque o tema "livros" é automaticamente relacionado ao pedagógico que, para elas, cabe apenas ao $\mathrm{CP}$, não importando a circunstância. Nessa perspectiva, fica evidente a cisão entre a dimensão administrativa e a pedagógica e, ainda, a falta de articulação no trabalho desta equipe gestora, evidenciando que estes profissionais não atuam de forma colaborativa ${ }^{5}$ (GOMBOEFF, 2017). Ficar horas na frente de um computador para registrar a escolha dos livros é significado como parte do trabalho pedagógico do CP, apesar de ser algo burocrático que toma seu tempo e o distancia do seu papel de formador.

A CP do relato 3 atende aos casos de indisciplina e violência a ponto de deixar de lado suas necessidades físicas: "Com uma escola cheia de problemas de todas as ordens, especialmente dos casos de indisciplina e violência, praticamente não tinha tempo de fazer xixi ou almoçar...".

Defende-se que assumir atribuições, muitas vezes, impostas pelo diretor ou pelas circunstâncias que não fazem parte da função do CP faz com que o diretor e os demais

\footnotetext{
${ }^{4}$ Disponível em:

file:///C:/Users/Micro/Desktop/Orientaes\%20gerais\%20escolha\%20do\%20PNLD\%202018\%20Literrio.pdf Acesso em: 04 fev. 2019.

${ }^{5} \mathrm{Na}$ colaboração, ao trabalharem juntos, os profissionais se apoiam, já que pretendem atingir objetivos comuns discutidos e acordados democraticamente, estabelecendo relações que caminham na direção da não hierarquização, da confiança mútua e da corresponsabilidade pela condução das ações (COSTA, 2006).
} 
profissionais acreditem que determinada tarefa é mesmo da coordenação, sobrecarregando o CP que, por sua vez, as toma para si e as integra às dimensões históricas da sua profissão (PLACCO e SOUZA, 2012).

Macedo (2014, p. 102) apontou em sua pesquisa que "há na dinâmica escolar e nos profissionais que ali atuam uma falta de clareza do que seria de fato, o papel do $\mathrm{CP}$, confundindo muitas vezes com os papéis de diretor e assistente de direção". O relato a seguir ilustra bem isso:

Relato $2-[\ldots]$ pouco depois que cheguei em casa, recebi uma mensagem, por meio do WhatsApp da diretora, dizendo que havia recebido a ata [de livros do PNLD escolhidos], mas que não conseguiria fazer o registro no sistema naquele dia porque tinha outras prioridades. Disse que no dia seguinte iria faltar e que estava deixando todos os seus dados e a senha de acesso ao sistema sobre minha mesa.

Fica claro que a diretora não tinha ciência do conteúdo do documento "Orientações Escolha PNLD Literário 2018” em termos do compromisso da escola acerca da moralidade e isonomia no processo de escolha ${ }^{6}$, que determina que a direção escolar é responsável pela guarda e sigilo da senha de escolha. Todos os dados e a senha de acesso ao sistema foram deixados em cima da mesa da CP, na sala dela, onde, geralmente, há grande circulação de professores, pais, alunos e funcionários.

Situações como essas, nas quais ao CP são atribuídas tarefas que não lhe pertencem, como digitar a relação de livros do PNLD no sistema, fazem com que às ações determinadas legalmente aos CPs, na maioria das vezes, juntem-se as atribuições que não são de fato da sua responsabilidade, o que acaba acarretando, frequentemente, para sua rotina, uma complexidade muito maior do que ela deveria contemplar, reverberando possíveis prejuízos ao acompanhamento pedagógico. A não compreensão do trabalho dos CPs gera também tensões (PLACCO, ALMEIDA e SOUZA, 2015) e, muitas vezes, problemas relacionais, resultando em atitudes autoritárias e, às vezes, agressivas e desrespeitosas, exemplificadas e analisadas no NS 2, apresentado a seguir.

\section{Núcleo 2 - A forma como as relações de poder podem se revelar nas escolas: "Saiu da sala gritando e criticando meu posicionamento... Fui atacado".}

\footnotetext{
${ }^{6}$ Disponível em: file://C:/Users/Micro/Desktop/Compromissos\%20da\%20escola\%20(1).pdf Acesso em: 04 fev.2019.
} 
O foco central deste núcleo é expor como as relações de poder se revelam nas situações cotidianas nas unidades escolares, por meio dos relatos dos CPs.

Este texto não intenciona criar uma visão única e genérica de nenhum membro da equipe gestora, ou seja, afirmar que determinado profissional é um "tirano" e o outro um "coitadinho". Deseja-se apenas refletir, de forma crítica, a partir de algumas situações cotidianas expostas pelos cinco CPs participantes, a fim de superar as diferentes significações sobre o papel do CP na escola que podem afetar o trabalho em equipe e a instituição escolar como um todo, deixando-a numa posição imobilizadora e burocrática. Defende-se que indagar a realidade engessada e as “verdades absolutas”, sem apontar culpados, é uma prática saudável e necessária de "resistência que permite aos indivíduos atuarem de forma mais genuína e mais combativa em relação às influências de poderes mais centralizadores” (MATE, 2009, p. 147).

Sabe-se que a escola é território de conhecimento, mas também espaço das relações de poder que afetam a dinâmica interna dos profissionais que atuam no ambiente escolar e a produção de certas formas de agir e pensar que vão se constituindo e concretizando historicamente de forma automática e acrítica. Os relatos abaixo exemplificam a ideia apresentada:

Relato 1 - A assistente de direção, ao invés de assumir o encaminhamento do trabalho [caso de indisciplina], saiu da sala gritando e criticando meu posicionamento de forma muito desrespeitosa e acionou a direção, que me abordou em minha sala, também com a voz alterada e agressiva.

Relato 3 - No dia seguinte fui trabalhar e tentei conversar com ele [diretor], foi quando gritou comigo e me disse que se eu quisesse conversar com ele seria em sua sala e não na minha. Desci para a sala dele e estavam todos os membros da gestão! Contou a versão dele, como se ele tivesse dado o recado igual para todos e só eu que não havia entendido. Deixou escapar ainda: "só você nunca entende". Fui humilhada.

Relato 5 - Fui atacado [pela diretora] em pleno PEA porque, pasmem, usei uma frase de Freud que diz: "Educar é um ato impossível". Pois bem, tivemos que ouvir no horário de formação a seguinte estultice: se a educação é impossível vão fazer outra coisa na vida... E por aí caminhou o discurso.

Placco e Souza (2012, p. 10-11) afirmam que “a direção é vista como o 'poder' em exercício, com uma função repressora e punitiva".

A partir do referencial teórico adotado, apreende-se que essa visão é construída ao longo da história, visto que todo fenômeno humano é social e todo fenômeno social não é natural, mas sim histórico e não pode ser compreendido senão em sua historicidade (BOCK, 1999). Entretanto, os seres humanos que são ativos e dotados de recursos subjetivos podem incorporar essa visão de direção escolar ou não. Os relatos acima indicam que alguns sujeitos, infelizmente, subjetivaram a realidade escolar dessa forma. Assim, é possível explicar que 
gritar, alterar a voz, falar de forma agressiva, atacar e até humilhar são atitudes inadequadas, mas cabíveis a quem significa seu cargo como instância de poder absoluto. Observa-se que, geralmente, essas atitudes inadequadas aparecem diante de situações nas quais há divergência nas significações dos profissionais envolvidos, na maioria das vezes, em relação ao papel do CP.

Os relatos a seguir revelam um posicionamento equivocado por parte do diretor:

\begin{abstract}
Relato 3 - [...] Existia uma desconfiança em meu trabalho e essa demonstração era clara e constante. Isso atrelado à postura distante em que se posicionava [o diretor] quando eu o procurava para tomar alguma decisão conjunta. Nunca podia falar comigo! [...] Com o tempo fui sabendo que todas as minhas falas e ações eram questionadas. Isto é, ele procurava informações sobre o que eu havia dito ou feito. [...)] Quando falava era por meio de mensagens de telefone ou por carta de comunicado. Quando conversava comigo era sempre hostil, demonstrava-se intolerante a tudo que eu falava e sempre comentava algo que ficou sabendo por terceiros. [...] Buscava arrancar de pais e professores reclamações a meu respeito. Como existia uma professora com o mesmo nome que o meu, certa vez uma mãe foi reclamar desta professora e sem entender o contexto da reclamação, já me chamou associando a reclamação a mim [...].
\end{abstract}

Apesar de o diretor escolar ser o profissional que responde legalmente pela escola, assumindo o papel central na estrutura hierárquico-administrativa, sua atuação não deve se pautar ao papel investigativo, não dialógico e avaliativo. Seu trabalho deve se caracterizar pela liderança que presume o administrativo, mas o conecta intrinsecamente ao pedagógico, visto que tais dimensões são inseparáveis (PARO, 1997). Desse modo, é primordial que o diretor e seus assistentes sejam parceiros do CP e desenvolvam, em conjunto com ele, o projeto da escola, bem como apoiem e acompanhem a formação docente, já que "o trabalho na escola só faz sentido no coletivo" (SOUZA, PETRONI e DUGNANI, 2015, p. 55).

Para que o diretor se transforme em líder e trabalhe coletivamente com todos os membros da equipe, segundo Aranha (2015) e Aranha e Aguiar (2016), é preciso que haja condições objetivas e subjetivas para tal. As autoras explicam que dentre essas mediações devese atentar para a formação do diretor e dos demais componentes da equipe. Assim, muitos equívocos acerca do papel do CP e das especificidades de cada cargo poderiam ser resolvidos se houvesse um momento formativo em que todos os profissionais (CPs, diretor e ADs) pudessem se confrontar com suas práticas, considerando sempre os aspectos sócio-históricos que as determinam, em uma perspectiva de trabalho colaborativo, reflexivo e crítico.

Clementi (2003, p. 62) afirma que "muitas estruturas de ensino nem sempre legitimam o papel do coordenador, garantindo-lhe espaço e status dentro da escola". É o que ilustra o 
relato 3: "Liguei na supervisão e pedi para me falarem se eu poderia ir até lá. Fui orientada a pedir autorização para o diretor. Eu estava chorando, desesperada”.

Percebe-se pelo relato que o CP na RMESP não tem autonomia para dirigir-se à Diretoria Regional de Ensino (DRE), local de trabalho do supervisor, sem a autorização do diretor. Essa falta de legitimação da profissão pode afetar a qualidade do trabalho educacional e essa legitimação deve passar também por um processo de profissionalização (CLEMENTI, 2003) - o que evidencia a urgência de uma formação que auxilie o CP e demais membros da equipe gestora a exercerem suas funções com autonomia suficiente para alinhar suas visões acerca da necessidade de um trabalho em equipe e das especificidades de cada cargo.

\section{Núcleo 3 - Reverberações do descompasso de significações sobre o papel do CP: "Faço análise uma vez por semana... Nossos processos formativos podem possibilitar grandes transformações".}

O foco central deste núcleo é explicitar e explicar como o descompasso de significações sobre o papel do $\mathrm{CP}$, muitas vezes, materializadas nas difíceis relações entre os membros da equipe gestora, podem se reverberar no cotidiano escolar.

As relações difíceis trazem à tona diversas reações e vários sentimentos e mexem com os aspectos subjetivos dos envolvidos, causando-lhes sofrimento. É o que revela o relato 3: "Isso é uma ferida aberta! (...) Quando conto me vem um choro de tristeza".

Diante das exigências e responsabilidades impostas ao CP, tanto pela legislação quanto pela significação do diretor em relação ao papel desse profissional e das relações de poder repressoras que circulam por muitas escolas, não é difícil sentir tristeza e dor, já que os sujeitos fazem a sua história, porém não a fazem sob uma conjuntura de sua escolha (MARX, 2011).

Marx (2004) afirma que o sofrimento ocorre porque humanos dependem das condições externas para garantir o viver. No entanto, sendo também ativos, tais condições incidem positiva ou negativamente sobre cada um. Desse modo, por um lado o sofrimento pode fazer os sujeitos adoecerem:

\footnotetext{
Relato 3 - Faço análise uma vez por semana e sei que é algo que tenho que trabalhar por mais um tempo. [...] Me dói. Tenho vergonha disso. Sei que não fiz nada errado. Mas é como se ele [diretor] tivesse plantado uma dúvida em mim. O tempo todo fico me policiando, se estou fazendo certo as coisas. Procuro ser metódica para não dar motivo para que reclamem de mim. Isso virou uma tortura. Sempre fui extrovertida. [...] Hoje em dia, entro muda e saio invisível. Tenho pavor de me expor e de as pessoas saberem quem eu sou. Tenho medo da crítica.
}

Por outro lado, o sofrimento pode resultar em formas de resistência e enfrentamento: 
Relato 5 - O percurso que escolhi como formativo começou a produzir rachaduras. É um movimento sem retorno. A apropriação de conceitos produziu mudanças, uma capacidade de autonomia reflexiva, logo de questionamento em relação à doxa escolar. [...] A cada dia que eu saía para as aulas, para as entrevistas, para realizar leituras, o que voltava não era o mesmo coordenador. Passei a olhar de forma muito crítica, porque estava sustentado em teorias, [...] nossos processos formativos podem possibilitar grandes transformações. Pode ser, sim, um divisor de águas. Nesse sentido os conflitos poderão ser mais duros. Se servir de consolo, nossas certezas estarão ancoradas em conceitos. Esse será o preço a ser pago.

Martins (2018, p. 135) afirma que o sofrimento é também "expressão da capacidade humana de tomada de consciência acerca do vivido [...]. O sofrimento resulta da identificação de obstáculos - que podem ser reais ou imaginários, no atendimento das necessidades que impulsionam a ação". A autora explica que se por um lado o sofrimento é positivo à medida que nos incita a fazer algo, por outro exige atenção aos recursos e ao modo pelo qual encara-se a situação.

De acordo referencial teórico-metodológico utilizado neste artigo, entende-se que o sofrimento surge como uma forma particular de relação do sujeito com as condições objetivas do seu trabalho, que além de ser o meio pelo qual atendemos às nossas necessidades, é uma mediação constitutiva importante do psiquismo humano.

Diante disso, compreende-se que é preciso cobrar das autoridades competentes um olhar mais atencioso, bem como medidas efetivas de melhora das condições de trabalho do $\mathrm{CP}$, a começar pela clareza e legitimação de sua função, principalmente entre a equipe gestora e possibilidades concretas para a efetivação do trabalho coletivo na escola - o que demanda formação capaz de subsidiar e envolver todos os profissionais para isso.

Assim sendo, a seguir, na conclusão, é apresentada a análise e a interpretação que constituem a última etapa de produção dos Núcleos de Significação: a etapa internúcleos, ou seja, a articulação de todos os núcleos (AGUIAR; OZELLA, 2013).

\section{Considerações Finais}

Ainda que a educação no Brasil historicamente esteja associada ao interesse político e econômico, há de se reconhecer que, nas últimas décadas, houve avanço no sistema educacional na perspectiva de maior acesso à educação básica e superior. No entanto, ainda há muito o que se fazer a fim de se garantir um ensino de qualidade para todos. Nesta perspectiva, conclui-se que a atuação do CP é uma mediação importante para que a aprendizagem se efetive e para isso é imprescindível que se invista em quem é responsável pela formação e quem ensina. Afinal, 
essa é a principal função da escola: ensinar, e, para isso, os professores têm que estar bem assistidos pelo $\mathrm{CP}$.

Para que isso se viabilize, o próprio CP necessita compreender bem a sua função. Sua atuação precisa se voltar para o acompanhamento e a intervenção, na perspectiva de subsidiar o professor a refletir sobre a sua prática e, ainda, para o ato de estudar a fim de ter bagagem teórica para compreender e atender às necessidades formativas dos docentes, planejando e executando a formação com eles de acordo com essas necessidades (CLEMENTI, 2003). Além disso, é preciso que o diretor e seus assistentes entendam que o papel do CP na equipe gestora deve se voltar para o âmbito das práticas formativas dentro da escola, bem como reconheçam a importância da formação continuada e a apoiem.

Diante do que foi exposto, pode-se afirmar que, muitas vezes, é difícil e desgastante lidar com as inúmeras e equivocadas atribuições impostas cotidianamente e enfrentar individualmente as relações opressivas presentes em muitas escolas ainda. Contudo, neste artigo, buscou-se defender que os processos formativos desenvolvidos no chão da escola têm potencial para grandes transformações.

\section{Referências}

AGUIAR, W. M. J.; OZELLA, S. Núcleos de significação como instrumento para a apreensão da constituição dos sentidos. Psicologia: Ciência e Profissão, São Paulo, v. 26, n. 2, p. 222247, 2006.

Apreensão dos sentidos: aprimorando a proposta dos núcleos de significação.

Revista Brasileira de Estudos Pedagógicos, Brasília, v. 94, n. 236, p. 299-322, 2013.

AGUIAR W. M. J.; SOARES, J. R.; MACHADO, V. C. Núcleos de Significação: uma proposta histórico-dialética de apreensão das significações. Cadernos de Pesquisa v.45 n.155 p.56-75, 2015.

ARANHA, E. M. G. Equipe gestora escolar: as significações que as participantes atribuem à sua atividade na escola - um estudo na perspectiva sócio-histórica. 2015. Tese (Doutorado em Educação: Psicologia da Educação) - Pontifícia Universidade Católica de São Paulo - PUC-SP, São Paulo, 2015.

ARANHA, E. M. G; AGUIAR, W. M. J. A dimensão subjetiva da gestão escolar: uma análise a partir dos sentidos e significados de participantes de equipes gestoras sobre a atividade desenvolvida. In: AGUIAR, W. M. J.; BOCK, A. M. B. (Orgs.). A dimensão subjetiva do processo educacional: uma leitura sócio-histórica. São Paulo: Cortez, 2016, p. 181-205.

BOCK, A. M. B. As aventuras do Barão de Munchhausen na Psicologia. São Paulo: Educ; Cortez; FAPESP, 1999. 
CLEMENTI, N. A voz dos outros e a nossa voz. In: ALMEIDA, L. R.; PLACCO, V. M. N. DE S. (orgs). $O$ coordenador pedagógico e o espaço da mudança. 2 ed. São Paulo: Edições Loyola, 2003, p. $53-66$.

COSTA, G. L. M. Mudanças da cultura docente em um contexto de trabalho colaborativo mediado pelas tecnologias de informação e comunicação. Perspect. ciênc. inf. [online], v.13, n.1, p.152-165, 2008.

GARRIDO, E. Espaço de Formação Continuada para o Professor-Coordenador. In: BRUNO, E. B. G., ALMEIDA, L. R. de, CHRISTOV, L. H. da S. (orgs.). O coordenador pedagógico e a formação docente. 4 ed. São Paulo: Loyola, 2003. p.9-15.

GOMBOEFF, A.L.M. Direção escolar e o trabalho colaborativo entre a equipe gestora: uma análise na perspectiva sócio-histórica. 2017. Dissertação. (Mestrado Profissional em Educação: Formação de Formadores) - Pontifícia Universidade Católica de São Paulo - PUC - SP, São Paulo, 2017.

MACEDO, S. R. B. A contribuição da formação continuada para a atuação dos coordenadores pedagógicos da Educação Infantil de São Bernardo do Campo. 2014. 194p. Dissertação (Mestrado em Educação) - Universidade de São Paulo - USP, São Paulo, 2014.

MARTINS, C. D. L. O sofrimento e /ou adoecimento psíquico do(a) professor(a) em um contexto de fragilização da formação humana. Cadernos Cemarx, Campinas, n. 11, p. 127 $144,2018$.

MATE, C. H. O coordenador pedagógico e as relações de poder na escola. In: PLACCO, V. M. N. DE S. ; ALMEIDA, L. R. (orgs.). O coordenador pedagógico e o cotidiano da escola. São Paulo: Edições Loyola, 2009, p.145 - 151.

MARX, K. Manuscritos econômico-filosóficos. São Paulo: Boitempo, 2004.

Grundrisse: manuscritos econômicos de 1857-1858: esboços da crítica da economia política. São Paulo: Boitempo, 2011.

PARO, V. Gestão democrática da escola pública. 3. ed. São Paulo: Ática, 1997.

PENTEADO, M. E. L. A Dimensão Subjetiva da Docência: significações de professores e gestores sobre "ser professor", produzidas em um processo de pesquisa e formação. 2017. Tese (Doutorado em Educação: Psicologia da Educação) - Pontifícia Universidade Católica de São Paulo - PUC-SP, São Paulo, 2017.

PLACCO, V. M. N.; SOUZA, V. L. T. O trabalho do coordenador pedagógico na visão de professores e diretores: contribuições à compreensão de sua identidade profissional. In: PLACCO, V. M. N. DE S.; ALMEIDA, L. R. (orgs.). O coordenador pedagógico: provocações e possibilidades de atuação. São Paulo: Edições Loyola, 2012, p. 9-20.

PLACCO, V. M. N.; ALMEIDA, L. R.; SOUZA, V. L. T. Retrato do coordenador pedagógico brasileiro: nuanças das funções articuladoras e transformadoras. In: PLACCO, V. 
M. N. DE S.; ALMEIDA, L. R. (orgs.). O coordenador pedagógico no espaço escolar: articulador, formador e transformador. São Paulo: Edições Loyola, 2015, p. 9-24.

SÃO PAULO (Município). Decreto no 54.453 de 11 de outubro de 2013. Fixa as atribuições dos profissionais de educação que integram as equipes escolares das unidades educacionais da rede municipal de ensino. São Paulo: Secretaria do Governo Municipal [2013]. Disponível em: https://www.sinpeem.com.br/lermais_materias.php?cd_materias $=7522 \&$ friurl=_-Decretono-54453-DOC-de-11102013-paginas-01-e-03- Acesso em: 13 fev. 2019.

SOUZA, V. L. T.; PETRONI, A. P.; DUGNANI, L. A. C. A dimensão do trabalho coletivo na escola: intervenções com a equipe gestora. In: PLACCO, V. M. N. DE S. ; ALMEIDA, L. R. (orgs.). O coordenador pedagógico no espaço escolar: articulador, formador $\mathrm{e}$ transformador. São Paulo: Edições Loyola, 2015, p. 53 - 72.

VIGOTSKI. L.S. A construção do pensamento e linguagem. 4. ed. São Paulo: Martins Fontes, 2001. 